\title{
Early Season Development of Micro/Nano-Morphology and Superhydrophobic Wetting Properties on Aspen Leaf Surfaces
}

\author{
George Christopher Tranquada, Jared Jennings Victor, Uwe Erb* \\ Department of Materials Science \& Engineering, University of Toronto, Toronto, Canada \\ Email: chris.tranquada@alumni.utoronto.ca, jared.victor.beale@utoronto.ca, ${ }^{*}$ uwe.erb@utoronto.ca
}

Received 8 July 2015; accepted 27 August 2015; published 31 August 2015

Copyright (C) 2015 by authors and Scientific Research Publishing Inc.

This work is licensed under the Creative Commons Attribution International License (CC BY). http://creativecommons.org/licenses/by/4.0/

\section{(c) (i) Open Access}

\begin{abstract}
The rapid growth and early development period of the dual-scale surface topography was studied on the adaxial leaf surfaces of two aspen tree species with non-wetting leaves: the columnar European aspen (Populus tremula "Erecta") and quaking aspen (Populus tremuloides). Particular attention was focused on the formation of micro- and nano-scale asperities on their cuticles, which was correlated with the development of superhydrophobic wetting behaviour. Measurements of the wetting properties (contact angle and tilt-angle) provided an indication of the degree of hydrophobicity of their cuticles. Scanning electron microscopy and optical profilometry micrographs were used to follow the growth and major morphological changes of micro-scale papillae and nano-scale epicuticular wax (ECW) crystals, which led to a significant improvement in non-wetting behaviour. Both species exhibited syntopism in the form of small and larger nano-scale ECW platelet morphologies. These findings provide additional support for earlier suggestions that due to fluctuations in leaf hydrophobicity throughout the growing season, canopy storage capacity may also vary considerably throughout this time period.
\end{abstract}

\section{Keywords}

Columnar European Aspen Leaves, Development of Superhydrophobic Leaf Surfaces, Epicuticular Wax Morphologies, Nano-Scale Wax Crystals, Quaking Aspen Leaves

\footnotetext{
*Corresponding author.
}

How to cite this paper: Tranquada, G.C., Victor, J.J. and Erb, U. (2015) Early Season Development of Micro/Nano-Morphology and Superhydrophobic Wetting Properties on Aspen Leaf Surfaces. American Journal of Plant Sciences, 6, 21972208. http://dx.doi.org/10.4236/ajps.2015.613222 


\section{Introduction}

Recent research efforts have focused on the characterization and understanding of non-wetting (Contact Angle (CA): $\left.110^{\circ}-150^{\circ}\right)$ and superhydrophobic $\left(\mathrm{CA} \geq 150^{\circ}\right)$ leaf surfaces which repel water droplets, allowing them to remain essentially dry (e.g. [1]-[8]). The classification of leaf hydrophobicity has been well articulated in the literature; leaves possessing a contact angle between $90^{\circ}-110^{\circ}$ are characterized as wettable, while non-wetting leaves can be classified as either non-wettable $\left(130^{\circ} \geq \mathrm{CA} \geq 110^{\circ}\right)$, highly non-wettable $\left(150^{\circ}>\mathrm{CA} \geq 130^{\circ}\right)$ or superhydrophobic $\left(\mathrm{CA} \geq 150^{\circ}\right)$ (i.e. [5] [9]). These leaves are covered by a thin hydrophobic waxy cuticle that acts as a multi-functional barrier between the plant and its external environment [10]. The cuticle, typically 0.1-10 $\mu \mathrm{m}$ in thickness, is a composite material which is comprised of a biopolyester matrix (cutin) with embedded intracuticular wax (ICW) lipids and an external layer comprised of protruding nano-scale epicuticular wax (ECW) morphologies which collectively repel water [11] [12]. Non-wetting and superhydrophobic leaf surfaces in particular often possess a unique hierarchical surface roughness; a combination of micro-scale papillae and nano-scale ECW morphologies, which act to inhibit wetting. This unique property was first discovered on the Lotus Leaf plant, which has the ability to emerge perfectly dry and clean following immersion in dirt contaminated waters [13] and is therefore termed as "The Lotus Effect" [1].

It has been suggested in numerous studies that the chemical composition of the ECW layer dictates the morphological type of these nano-scale asperities on the leaf's surface [14]-[17]. Even the slightest variations in chemical composition of wax constituents, for example, due to environmental changes, can result in the formation of inherently different wax morphologies [16], a principle known as "polymorphism” [2]. Nano-scale ECW asperities show "syntopism" when there is the occurrence of different wax crystalloid morphologies on neighbouring epidermal cells (micro-scale papillae) or one cell surface. It has been suggested that the shape and size of these morphologies are pre-determined by the nature of the intrinsic properties of these precursor wax molecules [14] [17].

Leaves from the aspen (Populus) species, were selected as a prime candidate for our study due to their unique biological significance. For example, it has been recently demonstrated [18] that the canopy storage capacity, or the amount of water retained following rainfall, post-drip and in the absence of wind, of quaking aspen and several other tree species native to Colorado is influenced by the degree of leaf hydrophobicity. Specifically, leaf surface storage and hence canopy storage capacity, are lower in leaves with greater hydrophobicity [18]. Aspen trees are among the most widely distributed trees in North America. Especially, quaking aspen and bigtooth aspen are known as pioneer trees that are first to regrow after forest fires, logging or in abandoned areas [19] [20]. Only recently has it been shown that both species have superhydrophobic leaf surfaces which facilitate easy water roll-off due to dual-scale hierarchical surface structure with ECW crystals [6] [8] [18] [21]. This water-repelling property is further enhanced by the flattened petioles on both species which allow the leaves to tremble in the slightest breeze [19] due to the reduced bending moment of the petioles compared with more rounded or rectangular petiole geometries [6]. Additionally the high degree of water repellency on these leaf surfaces may be functionally important in promoting higher photosynthetic efficiency during prolonged rainfall, as well as increasing water availability to their root systems [5] [18] [22].

Recent studies have reported on the significant changes in the surface morphology and wetting characteristics of several superhydrophobic and hydrophobic leaf surfaces throughout the growing season [8] [10] [16] [21] [23] [24]. Several of these studies have provided a possible link between various environmental stress factors such as temperature, relative humidity, wind and rain and the degradation of nano-scale wax crystals which ultimately resulted in the loss of superhydrophobic properties and onset of wettable leaf surfaces late in the growing season. This loss of superhydrophobicity may have important implications on canopy storage capacity, as decreases in leaf hydrophobicity could result in increased canopy and leaf water droplet storage and therefore potentially decreased hydrological inputs into the watershed as a consequence [5] [18]. Victor and Erb's study [21] was done on the surface structure of superhydrophobic quaking aspen (Populus tremuloides) leaves which was also successfully used as a biological blueprint to make superhydrophobic polymer surfaces by a template-type structure imprinting approach [7] [25]. However, the leaf surface characterization research did not address the initial development of the superhydrophobic properties in the early leaf growth stages, especially the formation of microand nano-scale morphologies on quaking aspen leaf surfaces. The current study provides a follow-up to this work and serves to investigate the early season formation of dual-scale surface topography and corresponding changes in wetting behaviour during this developmental period. 
Currently, there is a great deal of literature in the field of materials science dedicated to enhancing our understanding of the ways in which water droplets are repelled off various surfaces; these findings provide inspiration for the development of future artificial water-repellent materials and coatings [3]. However, it has been suggested that the significance of leaf hydrophobicity on canopy storage capacity is a largely unexplored topic in ecohydrology [5] [18]. The aim of this particular study is two-fold: firstly, to determine how the early season formation of micro-scale papillae and nano-scale epicuticular wax morphologies present on quaking aspen leaf surfaces result in pronounced changes in leaf hydrophobicity, and secondly to tentatively link these findings with their potential influence on ecohydrology, specifically consequences on canopy storage capacity as previously mentioned. In addition to the quaking aspen, a second closely related aspen species, the columnar European aspen (Populus tremula "Erecta") which has not been previously studied in this context to our knowledge, is included in this investigation.

\section{Materials and Methods}

\subsection{Sample Preparation}

All leaf samples were collected three times per week during their initial growth and development period (April $18^{\text {th }}$-May $21^{\text {st }}$, 2012) from trees in two wooded areas. Columnar European aspen (CEA) leaves were collected at the University of Toronto (Toronto, Ontario, Canada) in a garden plantation (N43 39.56 ', W079 $23.55^{\prime}$ ) while quaking aspen (QA) leaves came from a forest near Peterborough, Ontario, Canada (N44 ${ }^{\circ} 12.244^{\prime}, \mathrm{W}^{\circ} \mathrm{7}^{\circ} 23.23^{\prime}$ ). For both species all leaves were collected from one particular branch on the same tree at a height of less than 10 feet. The age of the trees was at least 15 and 10 years for columnar European and quaking aspen, respectively. All leaves were air dried, cut and mounted onto 1" $\times 1$ " Plexiglass ${ }^{\mathrm{TM}}$ coupons using double-sided carbon tape for wetting property measurements on their adaxial surfaces, and subsequently carbon coated for electron microscopy analysis. Additionally, leaf size measurements were recorded to compare the growth of leaf samples with growth of cuticular surface features (micro- and nano-scale asperities). A ruler was used to measure the length parallel and perpendicular to the petiole for a minimum of six leaves on each collection date. The average size and its standard deviation were recorded.

\subsection{Wetting Properties}

Both static and dynamic wetting properties of adaxial leaf surfaces were measured and correlated with the initial growth of micro-scale papillae and nano-scale epicuticular wax (ECW) morphologies. Static wetting properties were analyzed by measuring the contact angle (CA) created between sessile water droplets and the leaf surface. In addition, the tilt-angle (TA), or relative inclination angle for water droplet roll-off was measured. Note that the standard deviation (+/-) was also included for all wetting property (CA and TA) measurements. For CA measurements, leaf samples were aligned with a high resolution digital camera (Nikon D3000) equipped with a macro-lens (Nikon AF-S Micro Nikkor $40 \mathrm{~mm}$ ), which was situated on a tripod and used to capture images of no less than four $5 \mu \mathrm{L}$ droplets in various positions on each aspen leaf surface. Micrographs were analyzed using ImageJ software for contact angle measurements [26]. Tilt-angle measurements were completed using a controlled tilting-stage and $25 \mu \mathrm{L}$ water droplets.

\subsection{Surface Characterization}

The surface morphology development of aspen leaf surfaces was captured by Scanning Electron Microscopy (Hitachi S-4500 Cold-Field Emission SEM). Micrographs were taken at a sample tilt angle of $55^{\circ}$ in order to clearly distinguish variations in surface morphology. Characterization of nano-scale roughness asperities was completed using high magnification SEM micrographs to estimate the average height (perpendicular to leaf surface) and length (parallel to leaf surface) of both: i) shorter nano-scale crystals, as well as ii) larger elongated nano-morphologies during the initial growth period.

Optical Profilometry (WYKO NT-2000 with Wyko Vision 32 Software) was utilized to image 2-D and 3-D topographical surface plots of each leaf surface and detect changes to the size and shape of micro-scale features during the early stage growth phase. Using X-Y surface plots, the average peak to valley (p-v) height $(\mu \mathrm{m})$ and micro-scale feature base diameters $(\mu \mathrm{m})$ were measured. In order to obtain meaningful averages, a minimum of five micro-features were measured for each leaf specimen in both the $\mathrm{X}$ and $\mathrm{Y}$ directions, and at least two leaf 
specimens were analyzed per collection date. The standard deviation for all measurements was also included.

\section{Results and Discussion}

\subsection{Development of Superhydrophobic Wetting Behaviour}

Columnar European aspen leaves first emerged April 16 ${ }^{\text {th }}, 2012$ and were collected and analyzed from April $18^{\text {th }}$-May $21^{\text {st }}$, 2012. Correspondingly, quaking aspen leaves were collected beginning two days after bud break (May $3^{\text {rd }}$, 2012) until May 20 ${ }^{\text {th }}$, 2012. Figure 1 shows a progression of optical micrographs of water droplets, demonstrating the various stages of wetting on columnar European aspen leaf surfaces during this rapid growth period taken on April 27, May 7 and May 21, respectively. The first image (Figure 1(a)) illustrates a wettable surface captured in the very early stage of the growing season, which displayed a contact angle of $91^{\circ} \pm 3^{\circ}$, with a characteristic semi-spherical droplet shape. The second image (Figure 1(b)) was captured 10 days later, and demonstrates an increase in hydrophobicity to a non-wettable state, with $\mathrm{CA}=125^{\circ} \pm 5^{\circ}$. Finally the third image (Figure 1(c)) provides evidence that the leaf surface has attained a superhydrophobic wetting state, with a measured CA of $151^{\circ} \pm 2^{\circ}$.

The wetting properties (contact angle and tilt-angle) of columnar European and quaking aspen leaf surfaces measured during their initial growth and development period (spanning from April $18^{\text {th }}$ to May $21^{\text {st }}$ ) are shown in Figure 2. Wetting properties were also correlated with leaf growth as seen in Figure 3. Quaking aspen leaves

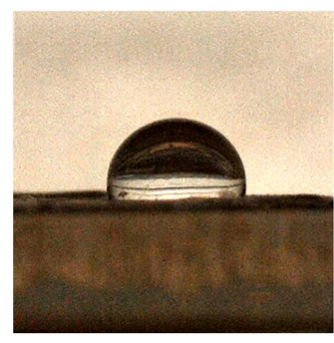

(a)

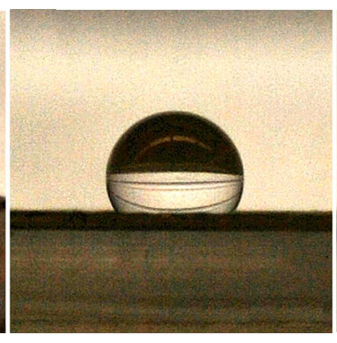

(b)

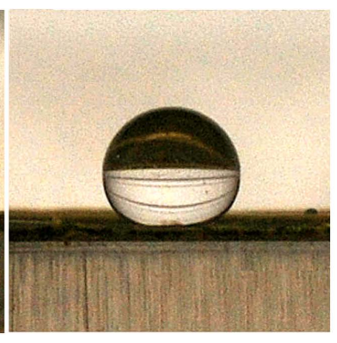

(c)

Figure 1. Changes in wetting behaviour on columnar European aspen leaf surfaces during early growth and development phase from: (a) wettable (CA $=91^{\circ}$, April 27) to (b) non-wettable (CA $=125^{\circ}$, May 7) and finally (c) superhydrophobic (CA $=151^{\circ}$, May 21).

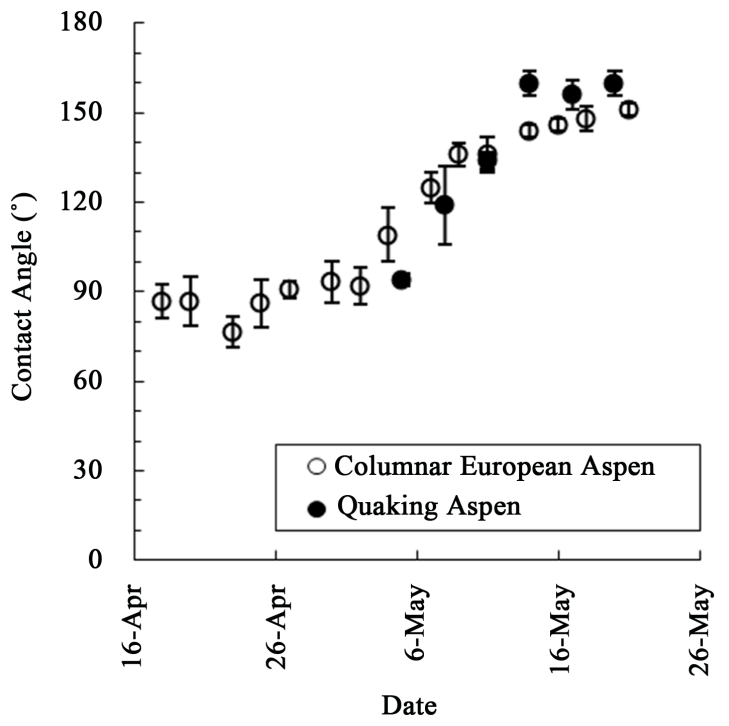

(a)

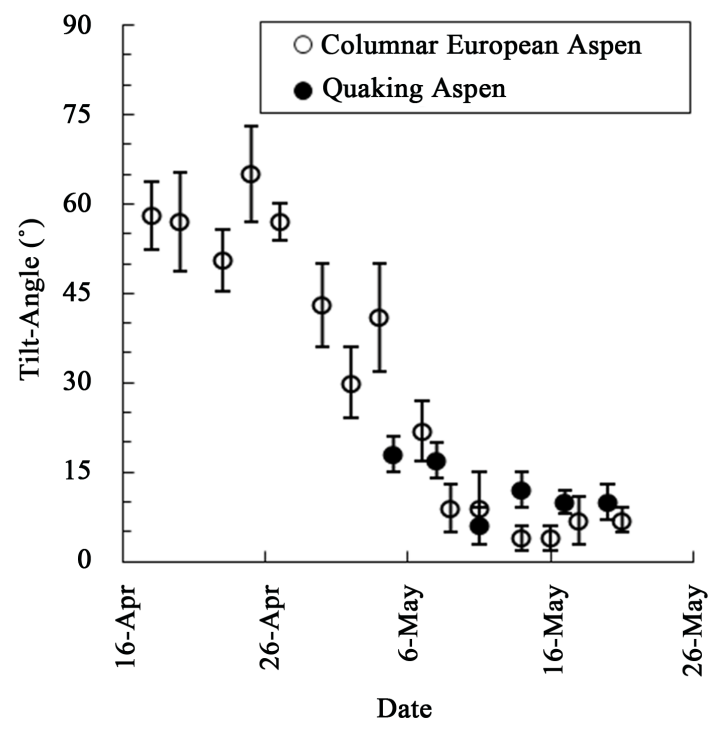

(b)

Figure 2. Contact angle (a) and tilt-angle (b) results measured during the rapid initial growth and development phase (April 18-May 21) of both columnar European aspen (Populus tremula "Erecta”) and quaking aspen (Populus tremuloides) adaxial surfaces. 


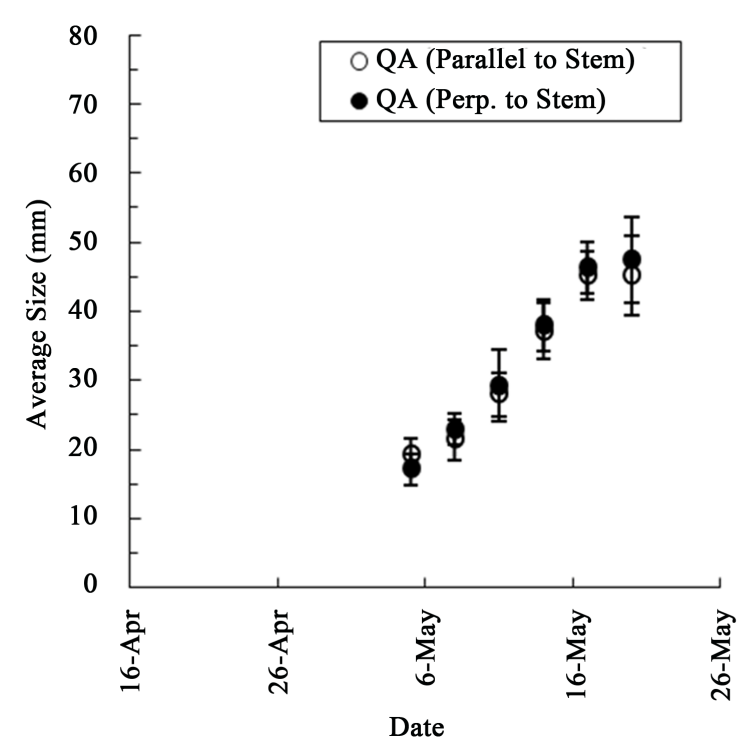

(a)

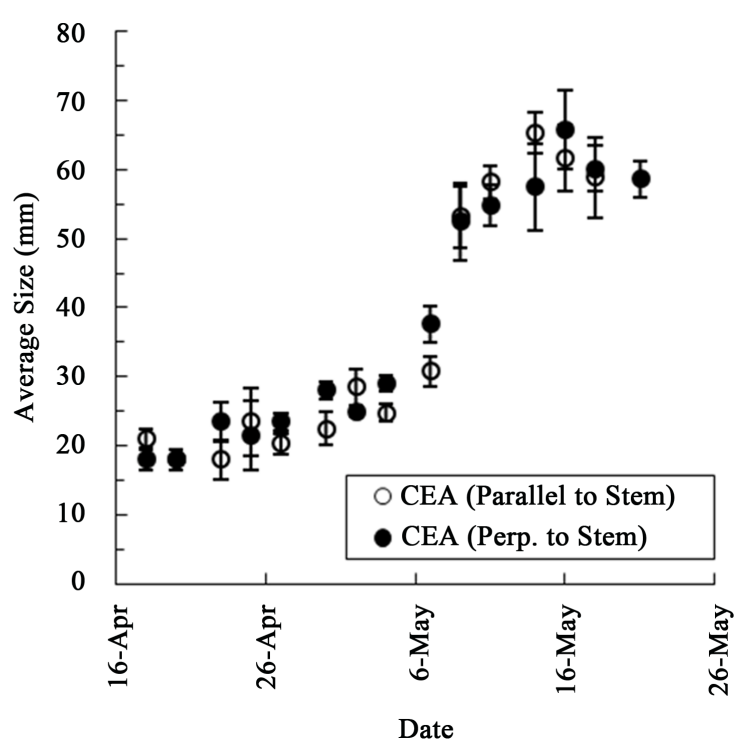

(b)

Figure 3. Growth of leaf samples parallel and perpendicular to primary stem for: (a) quaking aspen and (b) columnar European aspen leaves during initial growth and development phase.

were characterized by a ramp up in CA from a slightly hydrophobic surface $\left(94^{\circ}\right)$ to a superhydrophobic state $\left(160^{\circ}\right)$, which occurred over a 9 day period (May $5^{\text {th }}$ to $14^{\text {th }}$ ). This trend correlated with a simultaneous decrease in TA (as high as $18^{\circ}$ to as low as $6^{\circ}$ ), over the same timeframe. In addition, leaves were found to grow in both parallel (19 $\rightarrow 45 \mathrm{~mm}$ ) and perpendicular (from 17 to $47 \mathrm{~mm}$ ) dimensions relative to the petiole (Figure 3(a)). Columnar European aspen leaf surfaces showed two distinct phases in regards to their initial growth behaviour. Firstly, as shown in Figure 2, they experienced an early steady state non-wettable behaviour with no distinct increase/decrease in their contact and tilt-angles respectively (April $18^{\text {th }}$ to May $2^{\text {nd }}$ ). During this period leaves showed a relatively low growth rate parallel or perpendicular to their petioles (Figure 3(b)). Secondly, adaxial surfaces exhibited a ramp up in CA from a wettable $\left(92^{\circ}\right)$ to a superhydrophobic wetting state $\left(151^{\circ}\right)$ which correlated with a simultaneous decrease in TA (from $58^{\circ}$ to $7^{\circ}$ ) over a 19 day period (May $2^{\text {nd }}$ to $21^{\text {st }}$ ). This ramp up was also positively correlated with growth of leaf samples in both parallel and perpendicular directions (Figure 3(b)).

Quaking and columnar European aspen adaxial leaf surfaces experienced a similar trend in wetting properties, as was highlighted in Figure 2. Both species demonstrated a ramp up in contact angle from weakly hydrophobic $\left(\mathrm{CA} \cong 90^{\circ}\right)$ to superhydrophobic. However the quaking aspen attained superhydrophobicity of its adaxial leaf surfaces in a shorter time period (9 days) in comparison to the columnar European aspen (total of 32 days) and showed no initial steady state non-wetting period. The similarity in their ramp up from weakly hydrophobic to superhydrophobic behaviour may be attributed to the fact that these species are closely related [27]; the quaking aspen's Latin name (P. tremuloides), is an indication of its resemblance to the European aspen (P. tremula) [28]. Moreover, quaking and columnar European aspen trees separately, exhibit a high level of inter-genetic variability amongst species [29], which may explain the significant difference in the duration of ramp time to superhydrophobicity. It is interesting to note that the columnar European aspen's leaf morphology (large regularly spaced coarse-toothed serrations on leaf margin) better resembles the bigtooth aspen than the closely related quaking aspen leaf, which is characterized by much finer toothed serrations on its edges.

\subsection{Micro-Scale Roughness Characterization}

Optical profilometry results related to micro-scale papillae roughness for columnar European aspen and quaking aspen are summarized in Table 1 and Table 2 respectively. Results show the correlation between growth of micro-scale papillae in the vertical and horizontal dimensions, represented by the peak to valley (p-v) height and base diameter values, to the measured wetting properties during the leaf expansion period for both species: May 
Table 1. Correlation between papillae micro-scale roughness/ECW nano-scale roughness and wetting properties results for columnar European aspen leaf surfaces during early growth phase from May 2-21.

\begin{tabular}{|c|c|c|c|c|c|c|c|c|}
\hline \multirow{3}{*}{ Date } & \multicolumn{2}{|c|}{ Micro-Scale Roughness } & \multicolumn{4}{|c|}{ Nano-Scale Roughness } & \multicolumn{2}{|c|}{ Wetting Properties } \\
\hline & \multirow{2}{*}{$\begin{array}{c}\text { Base } \\
\text { Diameter } \\
(\mu \mathrm{m})\end{array}$} & \multirow{2}{*}{$\begin{array}{l}\text { Peak-Valley } \\
\text { Height }(\mu \mathrm{m})\end{array}$} & \multicolumn{2}{|c|}{ Nano-crystals } & \multicolumn{2}{|c|}{ Elongated Nano-morphologies } & \multirow{2}{*}{$\begin{array}{c}\text { Contact } \\
\text { Angle ( ( ) }\end{array}$} & \multirow{2}{*}{ Tilt-Angle ( $\left.{ }^{\circ}\right)$} \\
\hline & & & Height (nm) & Length (nm) & Height $(\mu \mathrm{m})$ & Length $(\mu \mathrm{m})$ & & \\
\hline May 2 & $9.3 \pm 4.4$ & $1.4 \pm 1.1$ & $232 \pm 54$ & $369 \pm 89$ & - & - & $92 \pm 6$ & $30 \pm 6$ \\
\hline May 4 & $11.5 \pm 3.0$ & $2.1 \pm 0.7$ & $409 \pm 68$ & $568 \pm 169$ & - & - & $109 \pm 9$ & $41 \pm 4$ \\
\hline May 7 & $15.8 \pm 4.4$ & $2.2 \pm 1.1$ & $452 \pm 77$ & $659 \pm 149$ & - & - & $125 \pm 5$ & $22 \pm 4$ \\
\hline May 14 & $20.1 \pm 4.9$ & $6.1 \pm 1.2$ & $591 \pm 109$ & $636 \pm 87$ & $1.1 \pm 0.3$ & $2.9 \pm 1.1$ & $144 \pm 2$ & $4 \pm 2$ \\
\hline May 21 & $17.4 \pm 4.0$ & $5.4 \pm 1.1$ & $626 \pm 102$ & $567 \pm 122$ & $0.9 \pm 0.3$ & $2.1 \pm 0.4$ & $151 \pm 2$ & $7 \pm 1$ \\
\hline
\end{tabular}

Table 2. Correlation between papillae micro-scale roughness/ECW nano-scale roughness and wetting properties results for quaking aspen leaf surfaces during initial growth phase from May 8-20.

\begin{tabular}{|c|c|c|c|c|c|c|c|c|}
\hline \multirow{3}{*}{ Date } & \multicolumn{2}{|c|}{ Micro-Scale Roughness } & \multicolumn{4}{|c|}{ Nano-Scale Roughness } & \multicolumn{2}{|c|}{ Wetting Properties } \\
\hline & \multirow{2}{*}{$\begin{array}{c}\text { Base } \\
\text { Diameter } \\
(\mu \mathrm{m})\end{array}$} & \multirow{2}{*}{$\begin{array}{l}\text { Peak-Valley } \\
\text { Height }(\mu \mathrm{m})\end{array}$} & \multicolumn{2}{|c|}{ Nano-Crystals } & \multicolumn{2}{|c|}{ Elongated Nano-Morphologies } & \multirow{2}{*}{$\begin{array}{c}\text { Contact } \\
\left.\text { Angle ( }{ }^{(}\right)\end{array}$} & \multirow{2}{*}{ Tilt-Angle $\left({ }^{\circ}\right)$} \\
\hline & & & Height (nm) & Length (nm) & Height $(\mu \mathrm{m})$ & Length $(\mu \mathrm{m})$ & & \\
\hline May 8 & $11.4 \pm 3.2$ & $2.9 \pm 0.6$ & $330 \pm 100$ & $420 \pm 70$ & - & - & $119 \pm 13$ & $17 \pm 3$ \\
\hline May 11 & $14.1 \pm 2.8$ & $4.7 \pm 1.1$ & $452 \pm 65$ & $549 \pm 180$ & - & - & $134 \pm 3$ & $6 \pm 3$ \\
\hline May 14 & $17.8 \pm 2.9$ & $6.1 \pm 1.0$ & $527 \pm 93$ & $521 \pm 117$ & $1.0 \pm 0.3$ & $3.4 \pm 1.0$ & $160 \pm 4$ & $12 \pm 3$ \\
\hline May 17 & $19.8 \pm 2.8$ & $5.9 \pm 1.1$ & $560 \pm 70$ & $513 \pm 110$ & $1.1 \pm 0.3$ & $3.7 \pm 1.2$ & $156 \pm 5$ & $10 \pm 2$ \\
\hline May 20 & $18.1 \pm 4.0$ & $5.0 \pm 1.1$ & $620 \pm 93$ & $478 \pm 89$ & $1.0 \pm 0.3$ & $2.8 \pm 0.8$ & $160 \pm 4$ & $10 \pm 3$ \\
\hline
\end{tabular}

$2^{\text {nd }}$ to $21^{\text {st }}$ for columnar European aspen and May $8^{\text {th }}$ to $20^{\text {th }}$ for quaking aspen. Values were not provided for the initial steady state period for columnar European aspen leaf species due to difficulties in resolving the height of relatively small micro-scale papillae.

Figure 4 illustrates a progression of images which show the growth stages of micro-scale papillae for both columnar European (Figures 4(a)-(c)), and quaking aspen (Figures 4(d)-(f)) leaves. Please note that scale levels are different in Figures 4(a)-(f), in order to bring out details of the surface structure. In regards to columnar European aspen leaf surfaces, the first image (Figure 4(a)) was captured on the first day of leaf development (April 18th). The 2-D and 3-D surface diagrams illustrate a relatively flat cuticle surface topography without any prominent micro-scale papillae features. Also the topographic images show that sub-micron roughness features seem to form on isolated islands (larger in scale than typical micro-papillae features, see Figure 4(a) and Figure 4(b)) and may expand or stretch during leaf growth, although little is known about the exact details of this mechanism. The middle image (Figure 4(b)) was captured prior to the rapid increase in hydrophobic wetting behaviour (May $2^{\text {nd }}$ ) showing the formation of irregular shaped micro-papillae. The final image (Figure 4(c)) was captured on May $14^{\text {th }}$ and shows the continued growth of papillae into their well-defined structure over the cuticle surface. Quaking aspen leaf surfaces, experience a similar trend in regards to their micro-morphological development. The first image (Figure 4(d)) captured on the first day of leaf development (May 5), illustrates a relatively flat cuticle. The middle image (Figure 4(e)) was captured just three days later (May 8) during the phase characterized by a rapid increase in hydrophobic wetting behaviour. Finally the last image (Figure 4(f)) was captured on May $17^{\text {th }}$, and shows the continued growth of papillae into their well-defined structure over the superhydrophobic cuticle surface.

\subsection{Nano-scale Roughness Development of Superhydrophobic Cuticles}

The surface morphology development on the nano-scale of columnar European aspen leaf surfaces was further 

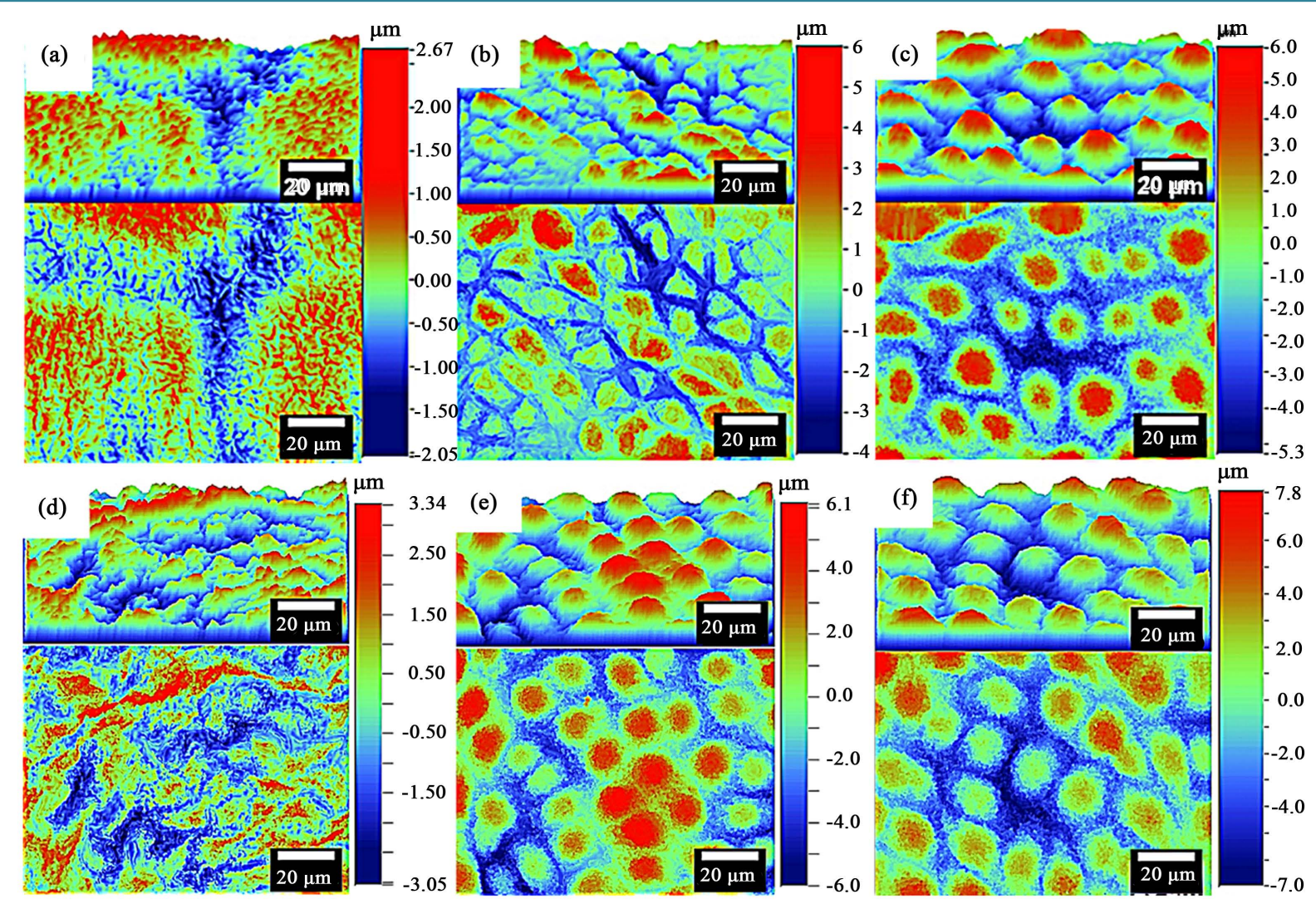

Figure 4. Optical profilometry micrographs showing both 3-D (top) and 2-D (bottom) adaxial leaf surface diagrams, collectively illustrating the progression of micro-papillae development, from: (a) April $18^{\text {th }}$ to (b) May $2^{\text {nd }}$ and finally (c) May $14^{\text {th }}$ for columnar European aspen leaves, and from (d) May $5^{\text {th }}$, to (e) May $11^{\text {th }}$, and to (f) May $17^{\text {th }}$ for quaking aspen leaf surfaces.

characterized using SEM during its initial growth phase (April $18^{\text {th }}$-May $21^{\text {st }}$ ). Plate 1 illustrates the four major morphological changes to the leaf's surface during this period of leaf expansion (Plates 1(a)-(h)), each at low (left) and high (right) magnifications.

The first stage of development was captured on April 25, where leaves exhibited a relatively flat surface topography (Plate 1(a) and Plate 1(b)). SEM micrographs show little surface roughness over large areas. The low magnification micrograph (Plate $\mathbf{1}(\mathrm{a})$ ) clearly shows the presence of a rare stoma on the upper leaf cuticle. Leaf surfaces were determined to be slightly hydrophilic in nature $\left(\mathrm{CA}=86^{\circ}\right)$ with high tilt-angle $\left(\mathrm{TA}=65^{\circ}\right)$ at this stage.

The second stage of growth, captured on May $4^{\text {th }}$ (Plate 1(c) and Plate 1(d)), demonstrates the development of micro-scale papillae and nucleation of sparsely distributed nano-scale ECW crystals on top of micro-scale papillae, typically 100 - $300 \mathrm{~nm}$ in thickness at the top and up to $500 \mathrm{~nm}$ at the bottom. Optical profilometry results (Table 1) show that papillae have grown vertically and horizontally to an average base diameter of 11.5 $\mu \mathrm{m}$ and peak to valley height of $2.1 \mu \mathrm{m}$. This dual-scale surface structure is correlated with a slightly higher contact angle $\left(\mathrm{CA}=109^{\circ}\right)$.

On the third stage of leaf surface structure development (captured May $7^{\text {th }}$ ), an increased density of nano-scale ECW platelets atop micro-scale papillae is observed (Plate 1(e) and Plate 1(f)). While their thickness remained relatively constant, ECW nano-crystals grew in height $(452 \mathrm{~nm})$ and length $(659 \mathrm{~nm})$, during this period (Table 1). There is also an increase in papillae size (base diameter $=15.8 \mu \mathrm{m}$ ) while pitch remains relatively constant (peak-valley height of $2.2 \mu \mathrm{m}$ ), as seen in Table 1. These changes were correlated with improved non-wetting properties $\left(\mathrm{CA}=125^{\circ}, \mathrm{TA}=22^{\circ}\right)$.

Finally the fourth stage of development (captured on May 14) displays evidence of syntopism [2], specifically co-existence of small nano-scale ECW platelet morphologies and larger nano-scale ECW platelets with irregular edges, also about 100 - $300 \mathrm{~nm}$ thick (Plate 1(g) and Plate 1(h)). Smaller, short nano-crystals were character- 

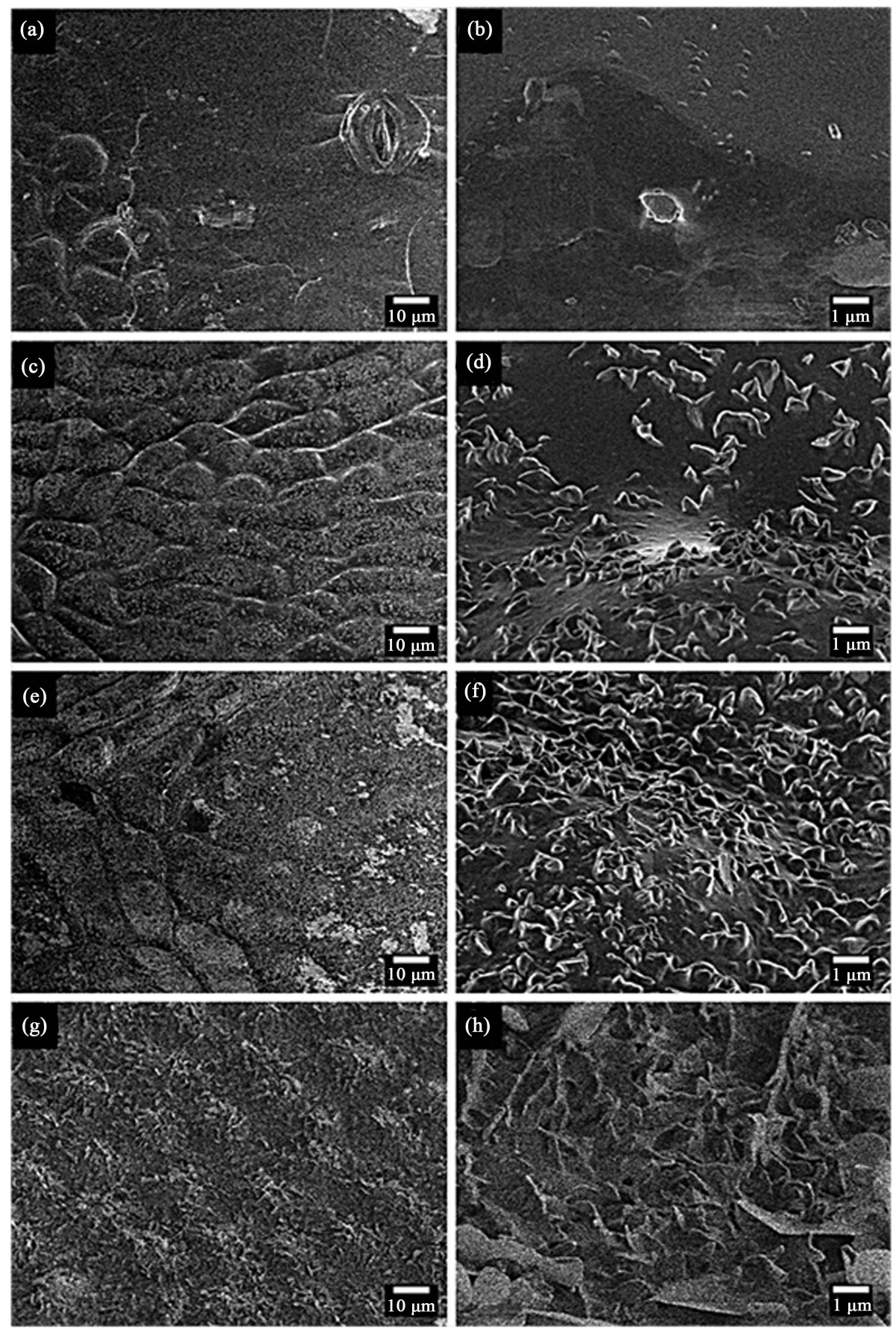

Plate 1. Low magnification (left) and high magnification (right) SEM micrographs showing development of CEA leaf surface captured: April $25^{\text {th }}((\mathrm{a}) \&(\mathrm{~b}))$, May $4^{\text {th }}((\mathrm{c}) \&(\mathrm{~d}))$, May $7^{\text {th }}$ (e) \& (f) and May $14^{\text {th }}($ (g) \& (h)).

rized by an average height and length of 591 and $636 \mathrm{~nm}$, respectively (Table 1), while the elongated ECW platelets were much larger in both average height $(1.1 \mu \mathrm{m})$ and length $(2.9 \mu \mathrm{m})$. This surface topography resulted in improved hydrophobicity $\left(\mathrm{CA}=144^{\circ}, \mathrm{TA}=4^{\circ}\right)$.

The surface morphology development of quaking aspen leaf surfaces was also characterized using SEM during early season leaf development (May $5^{\text {th }}$ to $14^{\text {th }}$ ). The original surface and the fully developed structure are shown in Plate 2. The initial stage of development was captured on May 5 (Plate 2(a) and Plate 2(b)), two days 

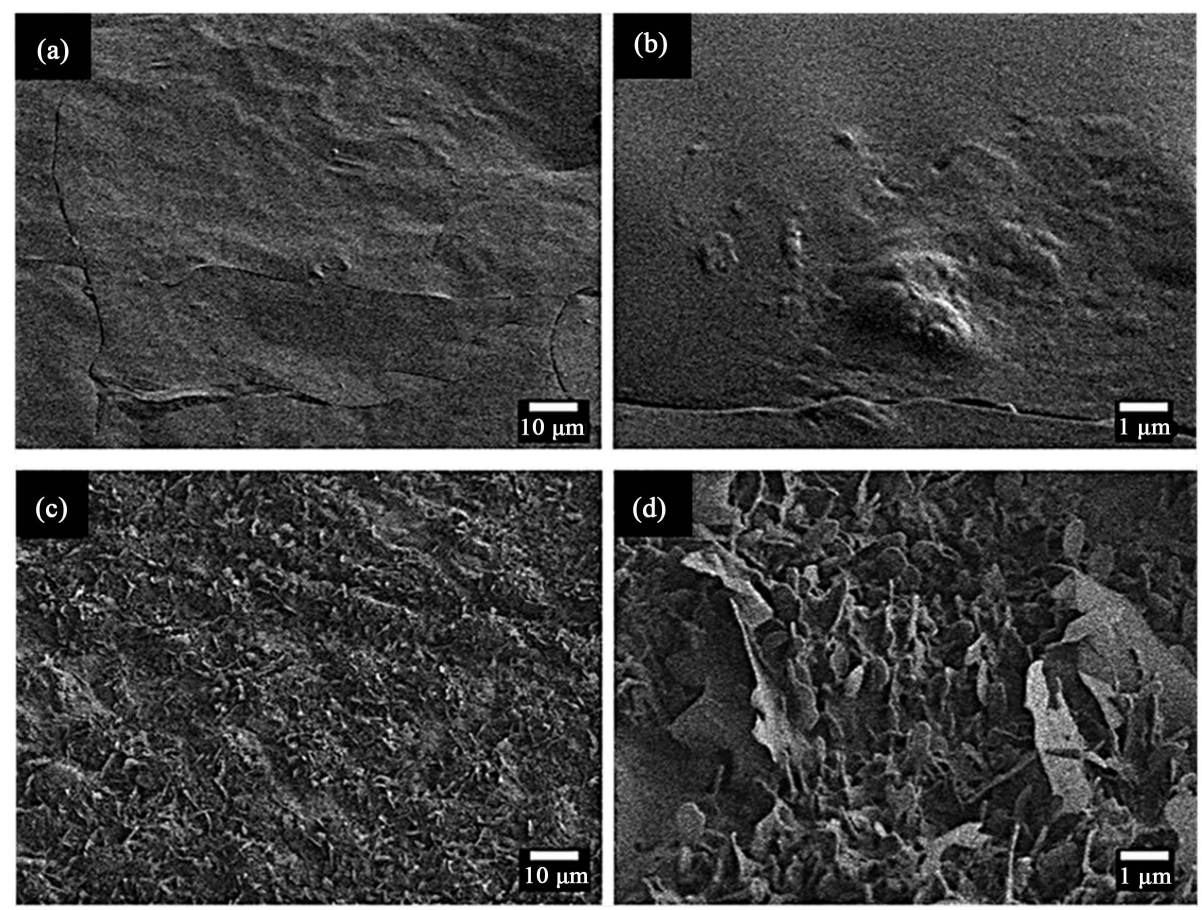

Plate 2. Low magnification (left) and high magnification (right) SEM micrographs showing development of QA leaf surface captured: May $5^{\text {th }}((\mathrm{a}) \&(\mathrm{~b}))$, and May $14^{\text {th }}((\mathrm{c}) \&(\mathrm{~d}))$.

following bud break. SEM Micrographs show a relatively flat leaf surface and the absence of well defined micro-scale papillae and nano-scale ECW morphologies. As a result, the wetting properties were found to be wettable in nature $\left(\mathrm{CA}=94^{\circ}\right)$.

Five days following initial bud break (May 8), micro-scale papillae had developed together with nucleation of superimposed nano-scale ECW morphologies (330 nm in height and $420 \mathrm{~nm}$ in length, Table 1). Optical profilometry observations presented in Table 2 demonstrate that micro-papillae are relatively short, with average peak-valley height of $2.9 \mu \mathrm{m}$ and average base diameter of $11.4 \mu \mathrm{m}$. These morphological changes support an increase in observed CA $\left(119^{\circ}\right)$ due to the beginning of a dual-scale hierarchical roughness formation.

On May 11, there is a further improvement in non-wetting behaviour $\left(\mathrm{CA}=134^{\circ}\right)$ which can be attributed to an increase in average micro-papillae size ( $\mathrm{p}-\mathrm{v}$ height $=4.7 \mu \mathrm{m}$, base diameter $=14.1 \mu \mathrm{m}$, Table 2 ) and potentially nano-roughness. SEM micrographs revealed nano-scale wax crystals with increased height (452 nm) and length $(549 \mathrm{~nm}$ ) (Table 2). This suggests the increase in both micro-papillae and nano-crystal size may contribute to enhanced hydrophobicity observed. More surprisingly, the observed TA has reduced significantly (from $17^{\circ}$ to $6^{\circ}$ ) within a 3 day period, which implies the increase in papillae size may also have a significant effect on the leaf's non-wetting behaviour.

Finally, the fourth stage of growth, captured on May 14 (Plate 2(c) and Plate 2(d)), is characterized by significant changes in nano-scale ECW morphologies, leading to the development of a cuticle surface with superhydrophobic wetting properties $\left(\mathrm{CA}=160^{\circ}\right.$ ). High magnification SEM micrograph (Plate 2(d)) reveal the co-existence of small nano-scale ECW platelets with average height and length of 527 and $521 \mathrm{~nm}$, respectively, (see Table 2 and Plate 2(d)) as well as larger nano-scale ECW platelets with irregular edges (on average $1 \mu \mathrm{m}$ in height and $3.4 \mu \mathrm{m}$ in width, Table 1). This co-existence of differing ECW platelet morphologies suggests the quaking aspen leaf also presents evidence of syntopism and the final structures of columnar European aspen (Plate 1(h)) and quaking aspen (Plate 2(d)) look indeed very similar. Finally, optical profilometry measurements on this date indicate a further increase in average papillae size (p-v height of $6.1 \mu \mathrm{m}$ and base diameter of $17.8 \mu \mathrm{m}$, Table 2).

In summary, SEM micrographs were used to correlate the development of micro- and nano-scale roughness asperities with ramp up in non-wetting behaviour. Not surprisingly, quaking and columnar European aspen also showed similarities in their initial stages of growth and development. Within a short period of time, micro fea- 
tures began to form, grew in size and nucleated nano-scale ECW nanocrystal and platelet morphologies superimposed on micro-scale papillose epidermal cells. The nucleated crystals grew in size and populated densely, which was followed by the formation of secondary nano-scale ECW platelets, providing evidence of syntopism. The increase in nano-crystal height and length observed on the surfaces of both columnar European and quaking aspen leaf cuticles, in conjunction with micro-papillae growth, positively influenced the non-wetting behaviour. In addition, co-existing elongated nano-scale ECW platelets were shown to improve the non-wetting behaviour of inherently hydrophobic leaf cuticles.

The exact mechanisms for nucleation and growth of the ECW morphologies are not known in the context of the studied leaf specimens. Various mechanisms have been suggested in the literature [10] [14] [16] [30], although to date no one theory has been accepted as universally applicable. One report has proposed [16] that wax generation and regeneration may occur by the simultaneous movement of waxes and water vapour through the cuticular membrane to its outer layer. The mechanism for growth of the nano-scale ECW morphologies is suggested to stem from a self-assembly of wax precursor molecules with a given chemical composition [17], which form crystalline wax morphologies through a layer-by-layer self-assembly process.

The aim of the current study was to address this issue from a morphological point of view. It was found that the early season formation of dual-scale surface topography on both quaking and columnar European aspen leaf surfaces resulted in a ramp up from wettable to superhydrophobic leaf wetting behaviour. These findings in conjunction with previous results [8] [21], demonstrate that superhydrophobic leaf surfaces may very well experience significant changes in leaf hydrophobicity over a growing season. Therefore, this suggests that canopy storage capacity may also in fact vary quite considerably throughout the year.

Varying wetting characteristics due to leaf surface morphology changes during the leaf lifetime is also important to consider in studies that attempt to relate stomata density of leaves and their corresponding wetting angle, both on adaxial and abaxial surfaces. An earlier hypothesis that stomata density is strongly correlated with wetting angle [31]-[33] has more recently been questioned in an extensive study [34] which shows that statistically such a relationship does not exist. Perhaps future studies in this area should consider at what time throughout the year the wetting properties are measured.

\section{Conclusion}

In conclusion, columnar European and quaking aspen leaf surfaces experienced a similar growth of their microand nano-scale asperities during their early season growth period, which led to the development of their unique superhydrophobic property. The increase in both relative size and density of nano-scale wax crystals was positively correlated with an increase in contact angle and decrease in tilt-angle. Quaking aspen leaf cuticles were found to achieve superhydrophobicity in a shorter time period (9 days) than columnar European aspen leaf samples (32 days). It was also found that syntopism, or the coexistence of ECW morphologies of different size lengths (specifically short nano-crystals as well as elongated nano-scale morphologies), appeared to enhance this unique extreme non-wetting behaviour. This particular study has served to support the importance of hierarchical roughness (at both the micro- and nano-scale levels) for this class of hydrophobic cuticles as an important criterion for the development of superhydrophobic wetting behaviour. Future work within this field of research should focus on characterization of changes in ECW chemistry during leaf development, which may help explain how these wax morphologies are developed. Specifically, establishing a link between wax micro/nanomorphology, and the type(s) of chemical constituents present in the ECW layer of each leaf species should be studied. In addition, further studies may also aim to establish the mechanism(s) for the nucleation and growth of ECW morphologies.

\section{Acknowledgements}

We would like to thank Mr. Sal Boccia for his help with scanning electron microscopy micrography. The financial support from the Natural Sciences and Engineering Research Council of Canada (NSERC) is greatly acknowledged.

\section{References}

[1] Barthlott, W. and Neinhuis, C. (1997) Purity of the Sacred Lotus, or Escape from Contamination in Biological Surfaces. Planta, 202, 1-8. http://dx.doi.org/10.1007/s004250050096 
[2] Barthlott, W., Neinhuis, C., Cutler, D., Ditsch, F., Meusel, I., Theisen, I. and Wilhelmi, H. (1998) Classification and Terminology of Plant Epicuticular Waxes. Botanical Journal of the Linnean Society, 126, 237-260. http://dx.doi.org/10.1111/j.1095-8339.1998.tb02529.x

[3] Bhushan, B. and Jung, Y.C. (2006) Micro- and Nanoscale Characterization of Hydrophobic and Hydrophilic Leaf Surfaces. Nanotechnology, 17, 2758-2772. http://dx.doi.org/10.1088/0957-4484/17/11/008

[4] Burton, Z. and Bhushan, B. (2006) Surface Characterization and Adhesion and Friction Properties of Hydrophobic Leaf Surfaces. Ultramicroscopy, 106, 709-719. http://dx.doi.org/10.1016/j.ultramic.2005.10.007

[5] Rosado, B.H.P. and Holder, C.D. (2013) The Significance of Leaf Water Repellency in Ecohydrological Research: A Review. Ecohydrology, 6, 150-161. http://dx.doi.org/10.1002/eco.1340

[6] Victor, J.J. and Erb, U. (2010) Superhydrophobic Structures on the Basis of Aspen Leaf Design. International Journal of Micro-Nano Scale Transport, 1, 323-333. http://dx.doi.org/10.1260/1759-3093.1.4.323

[7] Victor, J.J., Facchini, D. and Erb, U. (2012) A Low-Cost Method to Produce Superhydrophobic Polymer Surfaces. Journal of Materials Science, 47, 3690-3697. http://dx.doi.org/10.1007/s10853-011-6217-x

[8] Tranquada, G.C. and Erb, U. (2014) Morphological Development and Environmental Degradation of Superhydrophobic Aspen and Black Locust Leaf Surfaces. Ecohydrology, 7, 1421-1436. http://dx.doi.org/10.1002/eco.1468

[9] Aryal, B. and Neuner G. (2010) Leaf Wettability Decreases along an Extreme Altidudinal Gradient. Oecologia, 162, 1-9. http://dx.doi.org/10.1007/s00442-009-1437-3

[10] Koch, K., Bhushan, B. and Barthlott, W. (2008) Diversity of Structure, Morphology and Wetting of Plant Surfaces. Soft Matter, 4, 1943-1963. http://dx.doi.org/10.1039/b804854a

[11] Riederer, M. and Schreiber, L. (2001) Protecting against Water Loss: Analysis of the Barrier Properties of Plant Cuticles. Journal of Experimental Botany, 52, 2023-2032. http://dx.doi.org/10.1093/jexbot/52.363.2023

[12] Stark, R. and Tian, S. (2006) The Cutin Biopolyester Matrix. Annual Plant Reviews, Biology of the Plant Cuticle, 23, 126-144. http://dx.doi.org/10.1002/9780470988718.ch3

[13] Solga, A., Cerman, Z., Striffler, B.F., Spaeth, M. and Barthlott, W. (2007) The Dream of Staying Clean: Lotus and Biomimetic Surfaces. Bioinspiration and Biomimetics, 2, 126-134. http://dx.doi.org/10.1088/1748-3182/2/4/S02

[14] Jeffree, C.E., Baker, E.A. and Holloway, P.J. (1975) Ultrastructure and Recrystallization of Plant Epicuticular Waxes. New Phytologist, 75, 539-549. http://dx.doi.org/10.1111/j.1469-8137.1975.tb01417.x

[15] Jetter, R. and Schaffer, S. (2001) Chemical Composition of the Prunus laurocerasus Leaf Surface. Dynamic Changes of the Epicuticular Wax Film during Leaf Development. Plant Physiology, 126, 1725-1737. http://dx.doi.org/10.1104/pp.126.4.1725

[16] Neinhuis, C., Koch, K. and Barthlott, W. (2001) Movement and Regeneration of Epicuticular Waxes through Plant Cuticles. Planta, 213, 427-434. http://dx.doi.org/10.1007/s004250100530

[17] Koch, K. and Ensikat, H.J. (2008) The Hydrophobic Coatings of Plant Surfaces: Epicuticular Wax Crystals and Their Morphologies, Crystallinity and Molecular Self-Assembly. Micron, 39, 759-772. http://dx.doi.org/10.1016/j.micron.2007.11.010

[18] Holder, C.D. (2013) Effects of Leaf Hydrophobicity and Water Droplet Retention on Canopy Storage Capacity. Ecohydrology, 6, 483-490. http://dx.doi.org/10.1002/eco.1278

[19] Little, E.L. (2010) National Audobon Society Field Guide to North American Trees, Eastern Region. Chanticleer Press, New York, 323-327.

[20] Stam, B.R., Malechek, J.C., Bartos, D.L., Bowns, J.E. and Godfrey, E.B. (2008) Effect of Conifer Encroachment into Aspen Stands on Understory Biomass. Rangeland Ecology and Management, 61, 93-97. http://dx.doi.org/10.2111/06-156R2.1

[21] Victor, J.J. and Erb, U. (2013) Influence of Weather Conditions on the Surface Morphology and Wetting Behaviour of Superhydrophobic Quaking Aspen Leaves. American Journal of Plant Sciences, 4, 61-68. http://dx.doi.org/10.4236/ajps.2013.45A010

[22] Holder, C.D. (2012) The Relationship between Leaf Hydrophobicity, Water Droplet Retention, and Leaf Angle of Common Species in a Semi-Arid Region of the Western United States. Agricultural and Forest Meteorology, 152, 11-16. http://dx.doi.org/10.1016/j.agrformet.2011.08.005

[23] Hallam, N.D. (1970) Growth and Regeneration of Waxes on the Leaves of Eucalyptus. Planta, 93, 257-268. http://dx.doi.org/10.1007/BF00387646

[24] Neinhuis, C. and Barthlott, W. (1998) Seasonal Changes of Leaf Structure Contamination in Beech, Oak, and Ginkgo in Relation to Leaf Micromorphology and Wettability. New Phytologist, 138, 91-98. http://dx.doi.org/10.1046/j.1469-8137.1998.00882.x 
[25] Victor, J.J., Facchini, D., Palumbo, G. and Erb, U. (2012b) Biology Inspired Superhydrophobic Surfaces. Advanced Materials Research, 409, 814-819.

[26] ImageJ. http://imagej.nih.gov/ij/

[27] Einspahr, D.W. and Winton, L.L. (1976) Genetics of Quaking Aspen. Aspen Bibliography. Paper 5026. http://digitalcommons.usu.edu/aspen_bib/5026

[28] Barnes, B.V. (1978) Pollen Abortion in Betula and Populus (Section Leuce). The Michigan Botanist, 17, 167-172.

[29] Worrell, R. (1995) European Aspen (Populus tremula L.): A Review with Particular Reference to Scotland I. Distribution, Ecology and Genetic Variation. Forestry, 68, 93-105. http://dx.doi.org/10.1093/forestry/68.2.93

[30] Koch, K., Bhushan, B., Ensikat, H.J. and Barthlott, W. (2009) Self-Healing of Voids in the Wax Coating on Plant Surfaces. Philosophical Transactions of the Royal Society A: Mathematical, Physical and Engineering Sciences, 367, 1673-1688. http://dx.doi.org/10.1098/rsta.2009.0015

[31] Smith, W.K. and McClean, T.M. (1989) Adaptive Relationship between Leaf Water Repellency, Stomatal Distribution, and Gas Exchange. American Journal of Botany, 76, 465-469. http://dx.doi.org/10.2307/2444617

[32] Pandey, S. and Nagar, P.K. (2003) Patterns of Leaf Surface Wetness in Some Important Medicinal and Aromatic Plants of Western Himalaya. FLORA, 198, 349-357. http://dx.doi.org/10.1078/0367-2530-00107

[33] Brewer, C.A. and Nunez, C.I. (2007) Patterns of Leaf Wettability along an Extreme Moisture Gradient in Western Patagonia, Argentina. International Journal of Plant Sciences, 168, 555-562. http://dx.doi.org/10.1086/513468

[34] Holder, C.D. (2011) The Relationship between Leaf Water Repellency and Leaf Traits in Three Distinct Biogeographical Regions. Plant Ecology, 212, 1913-1926. http://dx.doi.org/10.1007/s11258-011-9963-6 